\title{
In Vitro Susceptibility Characteristics of Cryptococcus neoformans Varieties from AIDS Patients in Goiânia, Brazil
}

\author{
Orionalda de FL Fernandes/ ${ }^{+}$, Xisto S Passos, Lúcia KH Souza, André TB Miranda, \\ Carlos Henrique PV Cerqueira, Maria do Rosário R Silva
}

Instituto de Patologia Tropical e Saúde Pública, Universidade Federal de Goiás, Rua Delenda Resende de Melo, s/nº 74605-050 Goiânia, GO, Brasil

Sixty clinical isolates of Cryptococcus neoformans from AIDS from Goiania, state of Goiás, Brazil, were characterized according to varieties, serotypes and tested for antifungal susceptibility. To differentiate the two varieties was used L-canavanine-glycine-bromothymol blue medium and to separate the serotypes was used slide agglutination test with Crypto Check Iatron. The Minimal Inhibitory Concentration (MIC) of fluconazole, itraconazole, and amphotericin B were determined by the National Committee for Clinical Laboratory Standards macrodilution method. Our results identified 56 isolates as $\mathrm{C}$. neoformans var. neoformans serotype A and 4 isolates as $\mathrm{C}$. neoformans var. gattii serotype B. MIC values for C. neoformans var. gattii were higher than $\mathrm{C}$. neoformans var. neoformans. We verified that none isolate was resistant to itraconazole and to amphotericin $B$, but one $\mathrm{C}$. neoformans var. neoformans and three $\mathrm{C}$. neoformans var. gattii isolates were resistant to fluconazole. The presence of $\mathrm{C}$. neoformans var. gattii fluconazole resistant indicates the importance of determining not only the variety of $\mathrm{C}$. neoformans infecting the patients but also measuring the MIC of the isolate in order to properly orient treatment.

Key words: serotypes - antifungal susceptibility - Cryptococcus neoformans - Goiânia - Brazil

In the last years fungal infections have emerged as one of the major complications in immunocompromised patients (Pontón \& Quindós 1992). Cryptococcosis is the second most important fungal disease in human immunodeficiency virus (HIV)-positive patients, where disseminated infection is commonly fatal (Ito-Kuwa et al. 1994, Pinner et al. 1995, Patterson 1997, Calvo et al. 2001). In Brazil $4.5 \%$ of all opportunistic infections in AIDS patients have been reported as being caused by Cryptococcus neoformans (Ministério da Saúde 1999).

Epidemiological studies have demonstrated that distribuition of serotypes and varieties are considered to be regionally specific but $C$. neoformans var. neoformans (serotypes A and D) are most frequently isolated from AIDS patients throughout the world while C. neoformans var. gattii causes disease predominantly in normal individuals (Chen et al. 2000). C. neoformans var. gattii (serotypes B and C) has been prevalent in tropical and subtropical areas and behaves as a primary pathogen, similar in this respect to the other agents of systemic mycosis (Rozembaum \& Rios-Gonçalves 1994).

The increased prevalence of fungal infections and the introduction of new antifungal agents have intensified the need evaluation of antifungal susceptibility of $C$. neoformans.

Resistance has begin to emerge with $C$. neoformans var. neoformans in severely immunocompromized pati-

${ }^{+}$Corresponding author. Fax: +55-62-215.2057. E-mail: orionlisboa@ig.com.br

Received 26 May 2003

Accepted 21 July 2003 ents undergoing prolonged azole treatment (Alves et al. 1997, Espinel-Ingroff et al. 1998). Fluconazole is the drug that commands maintenance treatment protocols for AIDS patients (Witt et al. 1996).

In this study, we evaluated 60 clinical isolates of $C$. neoformans colleted from AIDS patients in Goiânia city and analyzed the occurrence of infections caused by the different varieties of $C$. neoformans. Then, we evaluate the in vitro susceptibilities to fluconazole, itraconazole, and amphotericin B.

\section{MATERIALS AND METHODS}

Isolates - A total of 60 C. neoformans isolates were obtained from AIDS patients with cryptococcal meningitis between October 2001 and April 2002, at Hospital de Doenças Tropicais de Goiânia, state of Goiás. Of these patients $49(81.7 \%)$ were males and $11(18.3 \%)$ were females. The age of the patient ranged between 15 and 56 years. $C$. neoformans isolates were identified by a melanin synthesis on DOPA medium, response positive urease, negative nitrates and ability to grow at $37^{\circ} \mathrm{C}$ (Kurtzman \& Fell 1998).

Agar media for physiological tests - L-canavanineglycine-bromothymol blue (CGB) agar, described by Kwon-Chung et al. (1982) was used to differentiate the two varietes of $C$. neoformans. Results were read after incubation at $37^{\circ} \mathrm{C}$ for 2 to 4 days.

Slide agglutination test - Agglutination serotyping was performed with eight factor specific sera Iatron Crypto-Check (Tokio, Japan) and interpreted as described by Ikeda et al. (1982).

In vitro susceptibility - Prior to testing, each isolate was grown on Sabouraud agar for $48 \mathrm{~h}$ at $35^{\circ} \mathrm{C}$. Suspensions were prepared in $0.85 \%$ saline to achieve a 0.5 McFarland standard by spectrophotometric measurement. Candida krusei ATCC 6258 was included on each test as quality control strain. 
MICs were determined for the $60 \mathrm{C}$. neoformans isolates according to the procedure of the macrodilution method of antifungal susceptibility testing of the National Committee for Clinical Laboratory Standards (NCCLS M27-A). Fluconazole (Pfizer, New York, US), itraconazole (Janssen Pharmaceuticals, Beerse, Belgium), and amphotericin B (Squibb, Princeton, NJ, US) were obtained as reagent-grade powder. Fluconazole was prepared to obtain two stock solution of $2560 \mu \mathrm{g} / \mathrm{ml}$ and $1920 \mu \mathrm{g} / \mathrm{ml}$, and the other antifungal drugs were prepared to obtain stock solutions of $3200 \mu \mathrm{g} / \mathrm{ml}$ and $2400 \mu \mathrm{g} / \mathrm{ml}$. Susceptibility testing was performed in RPMI 1640 medium with L-glutamine and without sodium bicarbonate (Sigma Chemical, St. Louis, MO, US) buffered to $\mathrm{pH} 7.0$ with 0.165 M morpholinepropanesulfonic acid (MOPS) buffer (Sigma) for three antifungal agents. The incubation was at $35^{\circ} \mathrm{C}$ for $72 \mathrm{~h}$. The final concentration range was 0.016 to 256 $\mu \mathrm{g} / \mathrm{ml}$ (stock solution of $2560 \mu \mathrm{g} / \mathrm{ml}$ ) and 0.012 to $192 \mu \mathrm{g} /$ $\mathrm{ml}$ (stock solution of $1920 \mu \mathrm{g} / \mathrm{ml}$ ) for fluconazole and 0.002 to $32 \mu \mathrm{g} / \mathrm{ml}$ (stock solution of $3200 \mu \mathrm{g} / \mathrm{ml}$ ) and 0.003 to 24 $\mu \mathrm{g} / \mathrm{ml}$ (stock solution of $2400 \mu \mathrm{g} / \mathrm{ml}$ ) for the other agents. Drug-free and yeast-free controls were included. All susceptibility tests were twice by each antifungal drug.

For the azoles, the MIC was established as the lowest antifungal concentration that inhibited $80 \%$ of the control growth $(0.2 \mathrm{ml}$ of growth control plus $0.8 \mathrm{ml}$ of uninoculated RPMI). For amphotericin B, endpoints were determined by recording the lowest concentration of the agent that prevented the appearance of visible growth (Espinel-Ingroff et al. 1996, NCCLS 1997). MIC 50 and MIC 90 to fluconazole, itraconazole and amphotericin B were calculated by inhibiting respectively $50 \%$ and $90 \%$ of the isolates of C. neoformans.

Fluconazole, itraconazole and amphotericin B breakpoints values for susceptibility have not yet been proposed by the NCCLS for C. neoformans. Nguyen and Yu (1998) recently adapted to C. neoformans, the fluconazole and itraconazole values proposed by this Committee for Candida spp. values found to be associated with therapeutic failure. In this away, Lozano et al. (1998), recommended that amphotericin MICs above $2 \mu \mathrm{g} / \mathrm{ml}$ indicates resistance to this polyene. Then, we defined resistance for amphotericin B MIC $\geq 2 \mu \mathrm{g} / \mathrm{ml}$, for fluconazole MIC $\geq 64 \mu \mathrm{g} / \mathrm{ml}$ and for itraconazole MIC $\geq 1$ $\mu \mathrm{g} / \mathrm{ml}$.

\section{RESULTS}

According to L-CGB agar, among 60 isolates of $C$. neoformans obtained from AIDS patients, 56 (93.3\%) were unable to grow on this medium and were shown to belong to var. neoformans, while $4(6.7 \%)$ isolates were able to grow and change the color of the medium from yellow to cobalt blue being characterized as var. gattii. Serotyping of this 56 isolates classified all of them as serotype A, and the 4 strains identified of $C$. neoformans var. gattii were serotype B.

Antifungal susceptibility testing - The MICs of all drugs except amphotericin B covered a broad range. MIC ranges for 56 C. neoformans var. neoformans were between 2 to $256 \mu \mathrm{g} / \mathrm{ml}$ for fluconazole, 0.047 to $0.75 \mu \mathrm{g} / \mathrm{ml}$ for itraconazole and 0.25 to $1 \mu \mathrm{g} / \mathrm{ml}$ for amphotericin B. MIC ranges for 4 C. neoformans var. gattii were between 24 to $256 \mu \mathrm{g} / \mathrm{ml}$ for fluconazole; 0.19 to $0.75 \mu \mathrm{g} / \mathrm{ml}$ for itraconazole and 0.75 to $1 \mu \mathrm{g} / \mathrm{ml}$ for amphotericin B. The fluconazole, itraconazole, and amphotericin B MICs for C. krusei ATCC 6258 isolate were $256,0.5$ and $0.5 \mu \mathrm{g} / \mathrm{ml}$, respectively, while the results obtained by NCCLS (NCCLS 1997) for this same specie are 16-64, 0.12-0.5 and $0.5-2.0 \mu \mathrm{g} / \mathrm{ml}$, respectively. In general the MICs values for each isolate duplicate were identicals.

All the isolates of $C$. neoformans serotype A were susceptible to amphotericin B and itraconazole, while $98.2 \%$ were susceptible to fluconazole. All C. neoformans serotype B were susceptible to amphotericin B and itraconazole, but $75 \%$ (3/4) were resistant to fluconazole.

\section{DISCUSSION}

In this study, $93.3 \%$ isolates $(56 / 60)$ were $C$. neoformans var. neoformans. All these isolates examined were serotype A, consistent with the predominant serotype isolated in most countries. This variety is prevalent among immunosuppressed patients, mainly AIDS patients (Mitchell \& Perfect 1995, Steenbergen \& Casadevall 2000). In this collection we identified as C. neoformans var. gattii serotype B four isolates. Human cryptococcosis due to this variety occurs predominantly in non-immunocompromised individuals (Rozembaum \& Rios-Gonçalves 1994). The apparent rarity of $C$. neoformans var. gattii infections in AIDS patients is an unexplained observation. Considering that plant species could be reservoirs for $C$. neoformans var. gattii (Lazera et al. 1998) and that most HIV-infected individuals reside in urban areas, they might be less exposed to en-vironmental sources of $C$. neoformans var. gattii than to sources to variety neoformans. The knowledge of the prevalence of serotypes in Goiânia, Brazil has not been determined.

There are no defined breakpoints by NCCLS for the azoles and amphotericin B for C. neoformans. For this reason the breakpoints were determined according Nguyen and Yu (1998) and Lozano et al. (1998). They define an isolate as resistant to fluconazole if the MIC was $\geq 64$ $\mu \mathrm{g} / \mathrm{ml}$, to itraconazole was $\geq 1 \mu \mathrm{g} / \mathrm{ml}$ and to amphotericin B was $\geq 2 \mu \mathrm{g} / \mathrm{ml}$. In accordance with these values, in our results all the isolates were susceptible to amphotericin $\mathrm{B}$ and itraconazole, and $93.3 \%$ were susceptible to fluconazole. In cryptococcosis, amphotericin B is considered the treatment of choice for the initial stages of therapy (White et al. 1994). Resistant isolates to this polyene have been observed in few patients. De Bedout et al. (1999) verified 2 isolates resistant to amphotericin B, but the number of patients whom amphotericin $B$ resistance has been demonstrated, continues to be low. Itraconazole and fluconazole has been also shown to be an effective alternative to amphotericin B in the treatment of cryptococcal meningitis and fluconazole is the most commonly used antifungal agent in maintenance therapy for this disease (Powderly 2000). The results of this study with relation to itraconazole and amphotericin B confirm the observations of Carrilo-Muñoz (1997) that verified all C. neoformans isolates were susceptible in vitro to these drugs studied. C. neoformans is extremely susceptible in vitro to itraconazole. Our data are similar to those reported 
by other investigators who used the same methodology (Alves et al. 2001). However some cases of meningitis due to $C$. neoformans resistant to fluconazole have been reported in AIDS patients (Peetermans et al. 1993, Berg et al. 1998).

In spite of the fact that $93.3 \%$ (56/60) of the isolates of C. neoformans tested were susceptible to fluconazole, $C$. neoformans var. gattii isolates exhibited higher MIC values than C. neoformans var. neoformans. Additionally, among the 4 isolates of the variety gattii that were tested, 3 were classified as resistant. C. neoformans var. gattii has been showed more resistant than C. neoformans var. neoformans by the other authors (Peetermans et al. 1993).

In conclusion, C. neoformans serotype A appeared to be most prevalent agent of cryptococcosis in Goiânia. Major differences of in vitro susceptibility were exhibited by the two varieties of $C$. neoformans. C. neoformans var. gattii isolates were more resistant than $C$. neoformans var. neoformans isolates. The presence of $C$. neoformans var. gattii isolates fluconazole resistant in this study, indicate the importance of determining not only the variety of $C$. neoformans infecting the patients but also measuring the MIC of the isolate in order to properly orient treatment.

\section{REFERENCES}

Alves SH, Lopes JO, Costa JM, Klock C 1997. Development secondary resistance to fluconazole in Cryptococcus neoformans isolated from a patients with AIDS. Rev Inst Med Trop São Paulo 39: 359-361.

Alves SH, Oliveira LT, Costa JM, Lubeck I, Casali AK, Vaintein MH 2001. In vitro susceptibility to antifungal agents of clinical and enviromental C. neoformans isolated in Southern of Brazil. Rev Inst Med Trop São Paulo 43: 3-9.

Berg J, Clancy CJ, Nguyen MH 1998. The hidden dander of primary fluconazole prophylaxys for patients with AIDS. Clin Infect Dis 26: 186-187.

Calvo MB, Colombo AL, Fischman O, Santiago A, Thompson L, Lazera M, Telles-F, Fukushima K, Nishimura K, Tanaka R, Myiaji M, Moretti-Branchini ML 2001. Antifungal susceptibilities, varieties, and electrophoretic karyotypes of clinical isolates of Cryptococcus neoformans from Brazil, Chile, and Venezuela. J Clin Microbiol 39: 2348-2350.

Carrillo-Muñoz AJ, Tur C, Estivill D, Montsant L, Carceller A, Hernández-Molina JM, Torres-Rodriguez JM 1997. Resistencia in vitro al fluconazol e itraconazol en aislamientos clínicos de Candida sp. y Cryptococcus neoformans. Rev Iberoam Micol 14: 50-54.

Chen S, Sorrell T, Nimmo G, Speed B, Currie B, Ellis D, Mariott D, Pfeiffer T, Parr D, Byth K 2000. Australian cryptococcal study group. Epidemiology and host-and variety-dependent charactestic of infection due to Cryptococcus neoformans in Australia and New Zealand. Clin Infect Dis 31: 499-508.

De Bedout C, Ordóñez N, Gómez BL, Rodriguez MC, Arango M, Restrpo A, Castañeda E 1999. In vitro antifungal susceptibility of clinical isolates of Cryptococcus neoformans var. neoformans and C. neoformans var. gattii. Rev Iberoam Micol 16: 36-39.

Espinel-Ingroff A, Barchiesi F, Hanze KC, Martinez-Suarez JV, Scalise G 1998. Standardization of antifungal susceptibility testing and clinical relevance. Med Mycol 36: 68-78.

Espinel-Ingroff A, Pfaller MA, Erwin ME, Jones RN 1996. Interlaboratory evaluation of "Etest" method for testing antifungal susceptibilities of pathogenic yeasts to five antifungal agents by using casitone agar and solidified RPMI
1640 medium with 2\% glucose. J Clin Microb 34: 848-852.

Ikeda R, Shinoda T, Fukazawa Y, Kaufman L 1982. Antigenic characterization of Cryptococcus neoformans serotypes and its application to serotyping of clinical isolates. J Clin Microbiol 16: 22-29.

Ito-Kuwa S, Nakamura K, Aoki S, Ninimiya K, Kato J, Vidotto V 1994. Serotyping of Cryptococcus neoformans isolated from Aids patients. Shigaku. Odontology 82: 360-364.

Kurtzman CP, Fell JW 1998. The Yeasts, a Taxonomic Study, 4th ed., Elsevier, Amsterdam, p. 657.

Kwon-Chung KJ, Polacheck I, Bennet JE 1982. Improved diagnostic medium for separation of Cryptococcus neoformans var. neoformans (serotypes A and D) and Cryptococcus neoformans var. gattii (serotypes B and C). J Clin Microbiol 15: 535-537.

Lazera MS, Cavalcanti MAS, Trilles L, Nishikawa MM, Wanke B 1998. Cryptococcus neoformans var. gattii-Evidence for a natural habitat related to decaying wood in a pottery tree hollow. Med Mycol 36: 119-122.

Lozano-Chiu M, Paetznick VL, Ghannoum MA, Rex JH 1998. Detection of resistance to amphotericine B among Cryptococcus neoformans clinical isolates: performances of threee different media assessed by using E-test and National Committee for Clinical Laboratory Standards M27 - A methodologies. J Clin Microbiol 36: 2817-2822.

Mitchell TG, Perfect JR 1995. Cryptococcosis in the era of AIDS 100 years after the discovery of Cryptococcus neoformans. Clin Microbiol 8: 515-548.

Ministério da Saúde 1999. Programa Nacional de Doenças Sexualmente Transmissíveis, Brasília, Brasil. Bol Epidemiol AIDS 1: 44.

NCCLS-National Committee for Clinical Laboratory Standards 1997. Reference method for broth diluition antifungal susceptibility testing of yasts; Aproved standard. Document M27-A, NCCLS, Pennsylvania, 19087, vol.17, p.1-29.

Nguyen MH, Yu CY 1998. In vitro comparative efficacy of voriconazole and itraconazole against fluconazole susceptible and resistance Cryptococcus neoformans isolates. Antimicrob Agents Chemother 42: 471-772.

Patterson TF 1997. Cryptococcosis in HIV-infected and nonHIV-infected host. J Infect Dis 1: S64-S69.

Peetermans W, Bobbaers H, Verhaegen J, Vandepitte J 1993. Fluconazole-resistant Cryptococcus neoformans var. gattii in AIDS patient. Acta Clin Belgica 48: 405-40.

Pinner RW, Hajjeh RHA, Powderly WG 1995. Prospects for preventing cryptococcosis in persons infected with human immunodeficiency virus. Clin Infect Dis 21: S103-S107.

Pontón J, Quindós G 1992. Las micosis en la década de 1990. Enf Infect Microbiol Clin 10: 385-388.

Powderly WG 2000. Cryptococcal meningitis in HIV-infected patients. Curr Infect Dis Rep 2: 352-357.

Rozenbaum R, Rios-Gonçalves AJ 1994. Clinical epidemiological study of 171 cases of cryptococcosis. Clin Infect Dis 18: 369-380.

Steenbergen JN, Casadevall A 2000. Prevalence of Cryptococcus neoformans var. neoformans (Serotype D) and Cryptococcus neoformans var. grubii (Serotype A) isolates in New York City. J Clin Microbiol 38: 1974-1976.

White DH, Armstrong D 1994. Cryptococcosis. Infect Dis Clin North American 8: 383-398.

Witt MD, Lewis RJ, Larsen RA, Milefchick EN, Leal MA, Haubrich RH, Richie JA, Edwards JE, Ghannoum MA 1996. Identification of patients with acute AIDS associated criptococcal meningitis who can be effectively treated with fluconazole. The role of antifungal susceptibility testing. Clin Infect Dis 22: 322-328. 